\title{
Incidence, morbidity, and associated factors for sepsis in women hospitalized for delivery: a nationwide retrospective observational population-based study in Canada
}

\section{Incidence, morbidité et facteurs associés au sepsis chez les femmes hospitalisées pour accouchement : une étude observationnelle rétrospective nationale basée sur la population au Canada}

\author{
Indranil Balki, HBSc • Leyla Baghirzada, MD, MPH • Andrew Walker, PhD • \\ Stephen Lapinsky, MB.BCh MSc • Mrinalini Balki, MBBS, MD $\mathbb{D}$
}

Received: 7 June 2021/Revised: 14 August 2021/Accepted: 8 September 2021/Published online: 22 December 2021

(C) Canadian Anesthesiologists' Society 2021

\begin{abstract}
Purpose The objective of this research was to examine the epidemiology of maternal sepsis in Canada.

Methods We conducted a population-based retrospective cohort study of women ( $\geq 20$ weeks gestation) hospitalized for delivery in all Canadian hospitals (excluding Quebec) between 1 April 2004 and 31 March 2017. Data were obtained from the national Canadian Institute for Health Information database and sepsis cases were identified via International Classification of Diseases, Tenth Revision, Canada (ICD-10-CA) codes. Our primary
\end{abstract}

This article is accompanied by an editorial. Please see Can J Anesth 2022; this issue.

Supplementary Information The online version contains supplementary material available at https://doi.org/10.1007/s12630021-02158-0.

I. Balki, HBSc

University of Toronto, Toronto, ON, Canada

L. Baghirzada, MD, MPH

Department of Anesthesiology, Perioperative and Pain Medicine, Cumming School of Medicine, University of Calgary, Calgary, $\mathrm{AB}$, Canada

\section{A. Walker, $\mathrm{PhD}$}

Department of Anesthesiology, Perioperative and Pain Medicine, Cumming School of Medicine, University of Calgary, Calgary, $\mathrm{AB}$, Canada

S. Lapinsky, MB.BCh MSc

Department of Medicine, Mount Sinai Hospital, University of

Toronto, Toronto, ON, Canada outcome was the number of hospitalizations for delivery associated with maternal sepsis. We further explored associations between patient characteristics, obstetric procedures/conditions, medical conditions, and maternal sepsis. Associations were presented using odds ratios (ORs) and 95\% confidence intervals (CIs).

Results There were 4,183 cases of sepsis in 3,653,783 hospitalizations for delivery during the study period, with an incidence of 114 (95\% CI, 111 to 118) per 100,000 hospitalizations and a mortality rate of $0.5 \%$. Annual sepsis rates per 100,000 hospitalizations ranged from a high of 160 (95\% CI, 146 to 177) in 2004 to 94 (95\% CI, 83 to 106) in 2011. Highest regional rates were observed in the Territories (224 per 100,000). Severe sepsis was seen in $14 \%(n=568)$ of all patients with sepsis, which was one or more of septic shock (15\%; $n=85)$, organ failure $(61 \%$; $n=345)$, intensive care unit admission (78\%; $n=443)$, or

M. Balki, MBBS, MD ( $\square)$

Department of Anesthesiology and Pain Medicine, Department of Obstetrics \& Gynaecology, and Department of Physiology, Mount Sinai Hospital, University of Toronto, 600 University Avenue, Room 7-405, Toronto, ON M5G 1X5, Canada e-mail: mrinalini.balki@uhn.ca

Lunenfeld-Tanenbaum Research Institute, Sinai Health System, Toronto, ON, Canada 
mortality (3\%; $n=19)$. Multivariable models showed that postpartum hemorrhage (OR, 2.9; 95\% CI, 2.7 to 3.2), Cesarean delivery (OR, 3.2; 95\% CI, 3.0 to 3.5), anemia (OR, 3.9; 95\% CI, 3.5 to 4.3), hysterectomy (OR, 4.9; 95\% CI, 3.6 to 6.6), chorioamnionitis (OR, 7.6; 95\% CI, 6.9 to 8.3), as well as cardiorespiratory, renal and liver conditions were associated with maternal sepsis.

Conclusion Maternal sepsis rates have been decreasing in Canada but remain higher than those in the UK and USA. Our study explored associations with maternal sepsis and shows that one in seven women with sepsis develop severe sepsis-related morbidity, which warrants risk stratification and health policy changes.

\section{Résumé}

Objectif L'objectif de cette étude était d'examiner l'épidémiologie du sepsis maternel au Canada.

Méthode Nous avons mené une étude de cohorte rétrospective basée sur la population de femmes $(\geq 20$ semaines de gestation) hospitalisées pour accouchement dans tous les hôpitaux canadiens excluant le Québec entre le $1^{\text {er }}$ avril 2004 et le 31 mars 2017. Les données ont été obtenues à partir de la base de données nationale de l'Institut canadien d'information sur la santé et les cas de sepsis ont été identifiés au moyen des codes de la Classification internationale des maladies, dixième révision, Canada (CIM-10-CA). Notre critère d'évaluation principal était le nombre d'hospitalisations pour accouchement associées à un sepsis maternel. Nous avons également exploré les associations entre les caractéristiques des patientes, les interventions / conditions obstétricales, les conditions médicales et le sepsis maternel. Les associations ont été présentées à l'aide de rapports de cotes (RC) et d'intervalles de confiance (IC) à $95 \%$.

Résultats Il y a eu 4183 cas de sepsis parmi les 3653783 hospitalisations pour accouchement au cours de la période à l'étude, avec une incidence de 114 (IC $95 \%, 111$ à 118) pour 100000 hospitalisations et un taux de mortalité de 0,5 $\%$. Les taux annuels de sepsis pour $100 \quad 000$ hospitalisations variaient d'un pic de 160 (IC $95 \%, 146$ à 177) en 2004 à 94 (IC $95 \%, 83$ à 106) en 2011. Les taux régionaux les plus élevés ont été observés dans les Territoires (224 pour 100 000). Un sepsis sévère a été observé chez $14 \%(n=568)$ des patientes atteintes de sepsis. Cette complication s'est manifestée en choc septique (15\%; $n=85)$, défaillance d'organe (61\%; $n=345)$, admission aux soins intensifs (78\%; $n=443)$, ou mortalité (3 \%; $n=19)$, ou en combinaison de ces complications. Des modèles multivariés ont montré que l'hémorragie du post-partum (RC, 2,9; IC $95 \%, 2,7$ à 3,2), l'accouchement par césarienne (RC, 3,2; IC 95\%, 3,0 à 3,5), l'anémie (RC, 3,9; IC $95 \%, 3,5$ à 4,3), l'hystérectomie (RC, 4,9; IC $95 \%, 3,6$ à 6,6), la chorioamnionite (RC, 7,6; IC $95 \%, 6,9$ à 8,3), ainsi que les affections cardiorespiratoires, rénales et hépatiques étaient associées au sepsis maternel.

Conclusion Les taux de sepsis maternel ont diminué au Canada, mais demeurent plus élevés qu'au Royaume-Uni et aux États-Unis. Notre étude a exploré les associations avec le sepsis maternel et montre qu'une femme sur sept atteinte de sepsis développe une morbidité sévère liée au sepsis, ce qui justifie une stratification des risques et des changements dans les politiques de santé.

Keywords sepsis · epidemiology · pregnancy · risk factors $\cdot$ morbidity

Sepsis is a life-threatening dysregulated multi-organ response to infection, and is one of the leading causes of death worldwide. ${ }^{1}$ Globally, sepsis during the peripartum period is estimated to result in up to $25-40 \%$ of maternal deaths. ${ }^{1}$ For every woman who dies of sepsis, up to 50 more may have sepsis-associated morbidity. ${ }^{2}$ In response to the increasing burden of sepsis, the World Health Organization (WHO) conducted a thorough literature review and recently passed a resolution (2017) identifying maternal sepsis as a high-priority area for research and development, in accordance with Sustainable Development Goals 3.1 and 3.2-to reduce maternal/ neonatal mortality and morbidity. ${ }^{3}$ Early diagnosis and management of sepsis is critical, since progression from sepsis to septic shock is associated with mortality rates greater than $40 \%{ }^{4}$

Prior retrospective population-based studies from the USA (2013-2016), UK (2011-2012), and the Netherlands (2004-2006) suggest that the incidence of sepsis in pregnancy may range from 21 to 47 per 100,000 deliveries. $^{2,5,6} \mathrm{Up}$ to $23 \%$ of all maternal deaths were sepsis-related in the study from the USA, ${ }^{5}$ and in the Netherlands, $79 \%$ of patients with severe sepsis required admission to the intensive care unit (ICU). ${ }^{6}$ The overall incidence rate increased from 2002 to 2015 in the USA, ${ }^{7}$ although there remains a great degree of variation based on the region and population studied. ${ }^{8,9}$

There is a high variability in the reported risk factors and outcome assessment for sepsis in previous epidemiological studies. ${ }^{2,5-7,10}$ Currently, there are no epidemiological analyses on maternal sepsis in Canada to guide prevention and management strategies. Considering increasing global burden of disease, and anticipated variation in the provincial and temporal distribution, there is a need to study this topic in a Canadian context. The objective of this study was to examine the 
epidemiology of sepsis in women hospitalized for delivery in Canada. We evaluated the incidence, temporo-regional trends, and associations with the progression to severe sepsis, and explored obstetric and medical conditions associated with maternal sepsis.

\section{Methods}

We conducted a retrospective population-based cohort study of all women hospitalized for delivery based on the Canadian nationwide Discharge Abstract Database (DAD) by the Canadian Institute for Health Information (CIHI), for the period 1 April 2004 to 31 March 2017. Institutional approval for the study was obtained from the University of Calgary Ethics Review Board (REB 19-1878, dated 19 November 2019), and the requirement for written informed consent was waived. The data were accessed from CIHI after their approval, and the data source involved deidentified information from all hospitalizations for delivery in Canada (excluding Quebec). With the exclusion of Quebec, we estimate that we captured approximately $75 \%$ of all Canadian hospitalizations for delivery during our study period.

Details of all hospitalizations are compiled by the CIHI. This information, including individual medical diagnoses, therapeutic and surgical procedures, and basic demographic characteristics are abstracted from medical records at hospital discharge by trained abstractors and compiled into the DAD. The CIHI DAD has been shown to be a feasible and comprehensive source for monitoring trends in maternal mortality and severe maternal morbidity. ${ }^{11-14}$ The rationale for choosing the time frame is that in the fiscal year of 2004/2005, all provinces and territories in Canada adopted International Classification of Diseases Tenth Revision, Canada (ICD-10-CA) and Canadian Classification of Interventions (CCI) coding, which is a Canadian version of ICD-10 proposed by the WHO. $^{15,16}$

Sepsis and severe sepsis categorization

The study population included all women with gestational age $\geq 20$ weeks, hospitalized for delivery in Canada based on the intervention and diagnostic codes for delivery. Data on women with abortive outcomes in early, ectopic, and molar pregnancies were not available. Cases of maternal sepsis were identified from the hospitalization records using the ICD-10-CA diagnosis codes (Electronic Supplementary Material [ESM] eTable 1), adapted from definitions from the CIHI. ${ }^{7,17}$ This required a diagnosis of systemic or disseminated infection potentially affecting organ systems. ${ }^{7}$ Diagnoses included under our categorization of maternal sepsis were one or more of septic shock, systemic inflammatory response with organ failure, necrotizing fasciitis, gas gangrene, toxic shock syndrome, bacteremia not otherwise specified, puerperal sepsis, streptococcal sepsis, infection from external stoma of urinary tract, gonococcal sepsis, salmonella sepsis, listerial sepsis, and other infections during labour including sepsis and other sepsis. The definition of severe sepsis was adapted from the UK Obstetric Surveillance System ${ }^{2}$ and CIHI, which included a patient meeting ICD-10 codes for at least one of the following: 1) septic shock, 2) systemic inflammatory response with organ system failure (includes severe sepsis), 3) organ failure, 4) necrotizing fasciitis, gas gangrene, acute meningococcemia or toxic shock syndrome, 5) ICU admission, or 6) death. The type of organ system failure was also determined using ICD-10CA coding (ESM eTable 1)., ${ }^{78}$ Data on patient demographics, labour and delivery, surgical procedures, and associated pre-existing medical and obstetrical conditions $^{18}$ were also collected using ICD-10-CA and CCI codes. ${ }^{14-16}$

\section{Outcome measures}

Our primary outcome was the incidence of maternal sepsis in women hospitalized for delivery in Canada. We further explored mortality and severe sepsis rates, the temporal trend, provincial distribution, and association of sepsis with obstetric and medical risk conditions, as well as association of these conditions with progression to severe sepsis.

\section{Statistical analysis}

We tabulated the frequency of sepsis by year and region, and expressed it per 100,000 hospitalizations with 95\% confidence intervals (CIs). Sepsis diagnostic etiologies and associated morbidity and mortality were presented as frequency (percentage) and incidence per 100,000 hospitalizations with 95\% CIs. We assessed the temporal trend in maternal sepsis using univariable linear regression and a conservative approach towards the calculation of standard errors through the use of a robust sandwich estimator. Data are presented as the average annual increase/decrease in maternal sepsis between 2004 and 2013 with 95\% CIs. The association between sepsis, severe sepsis, and hospitalizations after publication of the recommendation (September 2010) for antibiotic use prior to Cesarean delivery ${ }^{19}$ was investigated using univariate logistic regression and presented using an odds ratio (OR) and its 95\% CI. For this specific analysis, hospitalizations were dichotomized to prior and subsequent to implementation of recommendation and Cesarean delivery. Associations between demographic 
characteristics (age, gestational age, parity, multiple gestation and stillbirths), anesthetic techniques and sepsis vs no sepsis, and severe sepsis vs nonsevere sepsis were analyzed using univariable logistic regression and presented using rates of incidence (both number and percentage) and crude unadjusted ORs with their 95\% CIs.

We used multivariable logistic regression to analyze associations between delivery methods, surgical procedures, obstetric conditions, medical conditions and sepsis and severe sepsis. Analyses were separated into sepsis vs no sepsis, and severe sepsis vs nonsevere sepsis. Through results of crude associations found by univariable logistic regression and clinical relevancy, ORs were adjusted for demographic variables (age, parity, multiple gestation, stillbirths), delivery method (spontaneous vaginal, assisted vaginal, instrumental vaginal, Cesarean), surgical procedures (peripartum hysterectomy, dilatation and curettage, postpartum hemorrhage) and obstetrical conditions (placental abruption, chorioamnionitis, gestational diabetes, preeclampsia/eclampsia). ${ }^{10}$ Frequencies (percentages) as well as crude unadjusted and adjusted ORs with their 95\% CIs are presented for all associations. The codes relating to potential etiologies or diagnoses of sepsis are presented in a descriptive manner and case fatality rates were calculated by dividing the observed number of deaths associated with sepsis by the total number of hospitalizations for delivery. As the intent of our analysis was exploratory in nature, $P<0.05$ was deemed significant, $95 \%$ CIs were calculated, and no corrections were made to the level of significance to account for multiple comparisons within our regression analyses. Data were analyzed using IBM SPSS Statistics for Windows version 25.0 (IBM Corp., Armonk, NY, USA) and R Studio version 1.2.5019 with R statistical software version 3.6.1 (The $\mathrm{R}$ Project for Statistical Computing, Vienna, Austria).

\section{Results}

Maternal sepsis vs no sepsis

\section{Incidence and temporo-regional variation}

There were 4,183 cases of sepsis in 3,653,783 hospitalizations for delivery between 2004 and 2017 in Canada $(0.1 \%)$. Of the 4,183 hospitalizations, 3,875 $(92.6 \%)$ presented with one and 308 (7.4\%) presented with more than one of our defined conditions of sepsis (Table 1). This amounted to an incidence of 114 per 100,000 hospitalizations (95\% CI, 111 to 118), with a mortality rate of $0.5 \%$ (1:220 sepsis cases) (Table 1$)$. There was significant regional variation in sepsis rates (Fig. 1), with the highest rate observed in the Territories (224 per 100,000; 95\% CI, 167 to 301), and the lowest in New Brunswick (77 per 100,000; 95\% CI, 61 to 98). Annual sepsis rates per 100,000 hospitalizations ranged from a high of 160 (95\% CI, 146 to 177) in 2004 to 94 (95\% CI, 83 to 106) in 2011 (Fig. 2). The annual incidence of sepsis decreased with time (average annual decrease of 3.4 recorded cases of sepsis per 100,000 hospitalizations; $95 \%$ CI, -6.7 to $-0.01 ; P=0.05)$. The odds of developing sepsis in Cesarean deliveries were reduced after 2010 following implementation of prophylactic antibiotic use prior to incision $^{19}$ (OR, 0.72; 95\% CI, 0.67 to 0.79 ).

Puerperal sepsis was the leading diagnostic code contributing to sepsis $(72 \%)$, including that of sepsis with organ failure (34\%) and ICU admission (56\%) (Table 1). Severe sepsis was seen in $14 \%(n=568)$ of all patients with sepsis. These patients had one or more of septic shock (15\%, $n=85)$, organ failure $(61 \%, n=345)$, systemic inflammatory response with organ failure $(1 \%, n=7)$, ICU admission (78\%, $n=443)$, necrotizing fasciitis/gas gangrene/acute meningococcemia/toxic shock syndrome $(5 \%, n=28)$, or had died $(3 \%, n=19)$. Organ failure was observed in $8 \%(n=345)$ of all sepsis patients and in all 19 cases of maternal death (Table 1). Of the 3,875 hospitalizations with a single condition of sepsis, organ failure was present in $238(6 \%)$ of which 178 had one organ failure and 60 had multi-organ system failure. One hundred and seven of the 345 sepsis hospitalizations associated with more than one condition presented with organ failure $(35 \%)$ whereupon 62 had single organ failure and 45 had multi-organ system failure. Among hospitalizations with sepsis and organ failure, 30\% $(n=$ $105)$ had multi-organ system failure. The systems involved in organ failure were cardiovascular $(41 \%, n=199)$, respiratory $(22 \%, n=108)$, renal $(20 \%, n=96)$, hematologic $(12 \%, n=59)$, central nervous system $(2 \%$, $n=10)$, hepatic $(1.2 \%, n=6)$ and endocrine $(0.6 \%, n=3)$ [not mutually exclusive].

\section{Associations with maternal sepsis}

Baseline patient characteristics and their association with sepsis are displayed in Table 2. The odds of developing sepsis were $1.6(95 \% \mathrm{CI}, 1.5$ to 1.7$)$ and $1.2(95 \% \mathrm{CI}, 1.1$ to 1.3) higher in women $<25$ and $\geq 35$ years of age, respectively, compared with women 25-34 years of age. Premature delivery (20-36 weeks gestation) increased the odds of sepsis by 4.4 (95\% CI, 4.1 to 4.8$)$ compared with a term pregnancy of 37-40 weeks. Specifically, the odds of sepsis were 14.4 (95\% CI, 12.6 to 16.5) times higher in babies born between 20 and 28 weeks gestation. An increase in sepsis was also associated with deliveries beyond term pregnancy ( $\geq 41$ weeks) (OR, 1.3; 95\% CI, 
Table 1 Sepsis diagnostic etiologies, morbidity, and mortality

\begin{tabular}{|c|c|c|c|c|c|}
\hline Condition & $n(\%)^{\mathrm{a}}$ & $\begin{array}{l}\text { Incidence }(95 \% \mathrm{CI}) \\
\text { per } 100,000 \\
\text { hospitalizations }^{\mathrm{b}}\end{array}$ & $\begin{array}{l}\text { Organ } \\
\text { failure } \\
n(\%)^{\mathrm{c}}\end{array}$ & $\begin{array}{l}\text { ICU } \\
\text { admissions } \\
n(\%)^{\mathrm{d}}\end{array}$ & $\begin{array}{l}\text { Mortality } \\
n(\%)^{\mathrm{e}}\end{array}$ \\
\hline Puerperal sepsis & $2,990(72 \%)$ & $81.8(79.0$ to 84.8$)$ & $165(34 \%)$ & $249(56 \%)$ & $9(47 \%)$ \\
\hline Other infection during labour includes sepsis & $683(16 \%)$ & 18.7 (17.3 to 20.2$)$ & $43(9 \%)$ & $48(11 \%)$ & $2(11 \%)$ \\
\hline Other sepsis & $441(11 \%)$ & $12.1(11.0$ to 13.3$)$ & $139(29 \%)$ & $154(35 \%)$ & $10(53 \%)$ \\
\hline Streptococcal sepsis & $136(3 \%)$ & $3.7(3.2$ to 4.4$)$ & $21(4 \%)$ & $23(5 \%)$ & $0(0 \%)$ \\
\hline Bacteremia & $118(3 \%)$ & $3.2(2.7$ to 3.9$)$ & $12(3 \%)$ & $9(2 \%)$ & $1(5 \%)$ \\
\hline Septic shock & $85(2 \%)$ & $2.3(1.9$ to 2.9$)$ & $85(18 \%)$ & $69(16 \%)$ & $4(21 \%)$ \\
\hline $\begin{array}{l}\text { Infection following transfusion, infusion, and therapeutic } \\
\text { injection }\end{array}$ & $29(0.7 \%)$ & $0.8(0.6$ to 1.1$)$ & $2(0.4 \%)$ & $6(1 \%)$ & $0(0 \%)$ \\
\hline Necrotizing fasciitis & $23(0.5 \%)$ & $0.6(0.4$ to 1.0$)$ & $6(1 \%)$ & $16(4 \%)$ & $1(5 \%)$ \\
\hline Systemic inflammatory response with organ failure & $7(0.2 \%)$ & $0.2(<0.1$ to 0.4$)$ & $5(1 \%)$ & $5(1 \%)$ & $2(11 \%)$ \\
\hline Toxic shock syndrome & $4(0.1 \%)$ & $0.1(<0.1$ to 0.3$)$ & $3(0.6 \%)$ & $2(0.5 \%)$ & $0(0 \%)$ \\
\hline Listerial sepsis & $4(0.1 \%)$ & $0.1(<0.1$ to 0.3$)$ & $0(0 \%)$ & $0(0 \%)$ & $0(0 \%)$ \\
\hline Infection from external stroma of urinary tract & $2(<0.1 \%)$ & $<0.1(<0.1$ to 0.2$)$ & $0(0 \%)$ & $0(0 \%)$ & $0(0 \%)$ \\
\hline Salmonella sepsis & $2(<0.1 \%)$ & $<0.1(<0.1$ to 0.2$)$ & $0(0 \%)$ & $1(0.2 \%)$ & $0(0 \%)$ \\
\hline Gas gangrene & $1(<0.1 \%)$ & $<0.1(0$ to 0.2$)$ & $0(0 \%)$ & $0(0 \%)$ & $0(0 \%)$ \\
\hline Total hospitalizations with sepsis ${ }^{f}$ & $4,183(0.1 \%)$ & $114.5(111.1$ to 118.0$)$ & $345(8 \%)$ & $443(11 \%)$ & $19(0.5 \%)$ \\
\hline Hospitalization with one sepsis condition ${ }^{\mathrm{g}}$ & $3,875(92.6 \%)$ & $106.1(102.8$ to 109.4$)$ & $238(6 \%)$ & $328(9 \%)$ & $12(0.3 \%)$ \\
\hline Hospitalization with more than one sepsis condition ${ }^{\mathrm{h}}$ & $308(7.4 \%)$ & $8.4(7.5$ to 9.4$)$ & $107(35 \%)$ & $115(37 \%)$ & $7(2 \%)$ \\
\hline
\end{tabular}

$\mathrm{CI}=$ confidence interval; $\mathrm{ICU}=$ intensive care unit.

a Total number of diagnostic maternal sepsis codes recorded as per conditions presented is 4,525 in 4,183 total hospitalizations with sepsis. Of the 4,183 hospitalizations, 3,875 (92.6\%) presented with one and $308(7.4 \%)$ presented with more than one of our defined conditions. Percentages shown for each condition are in relation to total number of hospitalizations associated with maternal sepsis $(4,183)$. As such, summing of percentages for our defined conditions $\neq 100 \%$ (4,525 conditions in 4,183 hospitalizations).

b Incidence of maternal sepsis conditions presented per 100,000 hospitalizations captured in our database (3,653,783 hospitalizations)

c 345 hospitalizations associated with sepsis with one or more organ failures. 238 of the hospitalizations were associated with one sepsis condition whereupon 178 had one organ failure and 60 had multi-organ system failure. 107 of the 345 sepsis hospitalizations associated with more than one condition presented with organ failure whereupon 62 had single organ failure and 45 had multi-organ system failure. 481 total number of organ failure codes recorded in 4183 hospitalizations. This is because some hospitalizations had more than one sepsis condition and if that single hospitalization was associated with organ failure, that organ failure was captured for each condition.

d $443 \mathrm{ICU}$ admissions among all hospitalizations associated with sepsis. A number of hospitalizations were associated with more than one of our defined maternal sepsis conditions. In such instances a single ICU admission would have been captured by multiple sepsis conditions.

e 19 deaths occurred in hospitalizations associated with sepsis. A number of hospitalizations were associated with more than one of our defined maternal sepsis conditions. In such instances a single death would have been captured by multiple sepsis conditions.

${ }^{\mathrm{f}}$ Percentage of total hospitalizations associated with maternal sepsis presented in relation to total number of hospitalizations in our database $(0.1 \%)$. Percentages of organ failure, ICU admission and mortality presented in relation to hospitalizations only associated with maternal sepsis

g Percentage of hospitalizations associated with one of our defined conditions of maternal sepsis presented in relation to total number of hospitalizations associated with maternal sepsis $(92.6 \%)$. Percentages of organ failure, ICU admission and mortality presented in relation to hospitalizations only associated with one condition of maternal sepsis

${ }^{\mathrm{h}}$ Percentage of hospitalizations associated with one or more of our defined conditions of maternal sepsis presented in relation to total number of hospitalizations associated with maternal sepsis (7.4\%). Percentages of organ failure, ICU admission and mortality presented in relation to only hospitalizations associated with more than one of our defined conditions with maternal sepsis.

1.2 to 1.4). Women hospitalized for their first delivery (OR, 2.0; $95 \%$ CI, 1.8 to 2.2) and those hospitalized for their fifth delivery or more (OR, 1.6; 95\% CI, 1.3 to 2.0 ) had increased odds of sepsis compared with women with parity of two or three. Both multiple gestation (OR, 2.9; 95\% CI,
2.5 to 3.3 ) and stillbirths (OR, 8.8; 95\% CI, 7.6 to 10.2) were associated with higher odds of sepsis.

Associations between maternal sepsis and delivery method, obstetrical surgical procedures, and obstetric and medical conditions are presented in Table 3. Cesarean (OR, 
Fig. 1 Regional distribution of maternal sepsis in Canada.

Provinces $-\mathrm{PEI}=$ Prince

Edward Island; NS = Nova

Scotia; NB = New Brunswick;

$\mathrm{NL}=$ Newfoundland; $\mathrm{ON}=$

Ontario; $\mathrm{MB}=$ Manitoba; $\mathrm{SK}=$

Saskatchewan; $\mathrm{AB}=$ Alberta;

$\mathrm{BC}=$ British Columbia.

Territories $-\mathrm{YK}=$ Yukon; NT = Nunavut; NWT $=$ Northwest

Territories
Incidence, per 100k deliveries

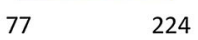

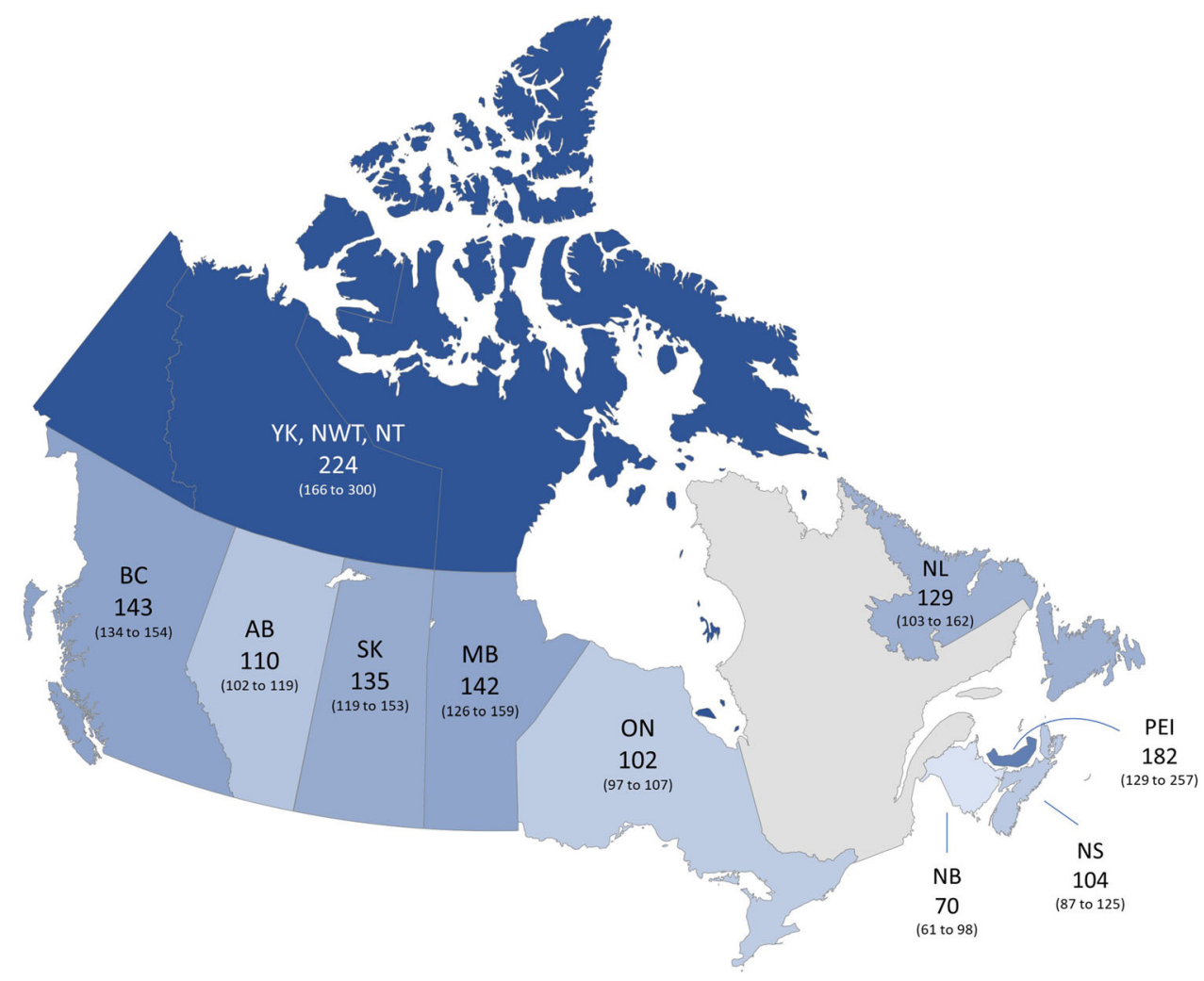

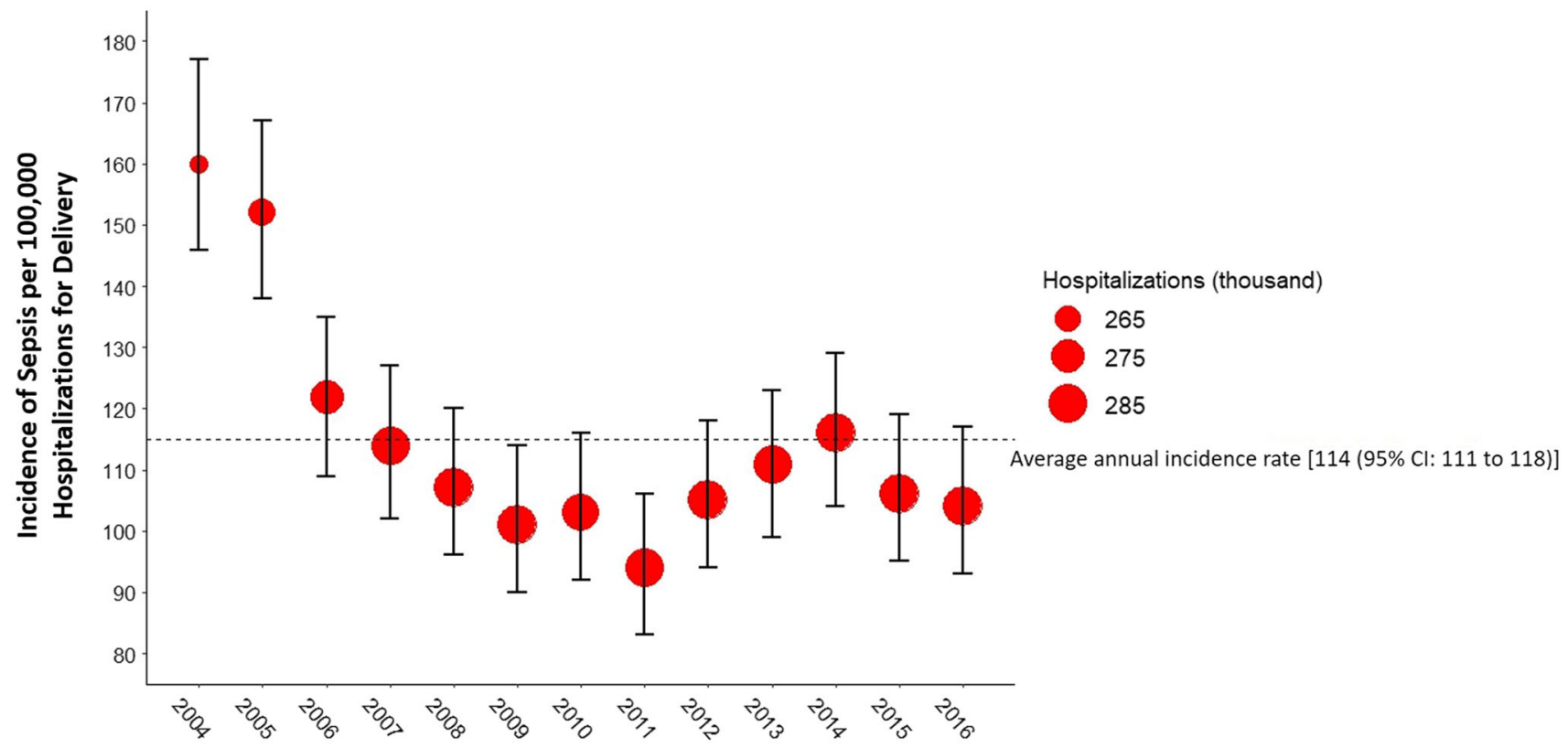

Fiscal Year

Fig. 2 Temporal trends of maternal sepsis in Canada

3.2; 95\% CI, 3.0 to 3.5) and instrumental vaginal (OR, 1.5; $95 \% \mathrm{CI}, 1.3$ to 1.7$)$ deliveries had higher odds of sepsis than assisted vaginal delivery. The odds of sepsis increased with emergent $(704 / 139,504)$ compared with elective (1,525/883,058) Cesarean deliveries (unadjusted OR, 2.9; 95\% CI, 2.7 to $3.2 ; P<0.001)$. Among those receiving 
Table 2 Associations between patient characteristics and maternal sepsis

\begin{tabular}{|c|c|c|c|}
\hline Characteristics & Sepsis $(\%) n=4,183$ & No sepsis $(\%) n=3,649,600$ & Unadjusted odds ratio* $(95 \% \mathrm{CI})$ \\
\hline \multicolumn{4}{|l|}{ Maternal age (years) } \\
\hline$<25$ & $1,096(26)$ & $686,102(19)$ & $1.6(1.5$ to 1.7$)$ \\
\hline $25-34$ & $2,262(54)$ & $2,252,127(62)$ & Reference \\
\hline $35-39$ & $649(16)$ & $587,626(16)$ & $1.1(1.0$ to 1.2$)$ \\
\hline$\geq 40$ & $176(4)$ & $123,741(3)$ & $1.4(1.2$ to 1.7$)$ \\
\hline \multicolumn{4}{|l|}{ Gestational age (weeks) } \\
\hline $20-28$ & $250(6)$ & $21,167(0.6)$ & $14.4(12.6$ to 16.5$)$ \\
\hline $29-32$ & $164(4)$ & $25,527(0.7)$ & $7.9(6.7$ to 9.2$)$ \\
\hline $33-36$ & $365(9)$ & $168,942(5)$ & $2.6(2.4$ to 3.0$)$ \\
\hline $37-40$ & $1,853(44)$ & $2,260,199(62)$ & Reference \\
\hline$\geq 41$ & $390(9)$ & $370,939(10)$ & $1.3(1.2$ to 1.4$)$ \\
\hline Unknown & $1,161(28)$ & $802,826(22)$ & $1.8(1.6$ to 1.9$)$ \\
\hline \multicolumn{4}{|l|}{ Parity } \\
\hline 0 & $2,057(49)$ & $1,297,177(36)$ & $2.0(1.8$ to 2.2$)$ \\
\hline 1 & $708(17)$ & $1,035,479(28)$ & $0.87(0.77$ to 0.98$)$ \\
\hline $2-3$ & $437(10)$ & $555,139(15)$ & Reference \\
\hline$\geq 4$ & $130(3)$ & $103,022(3)$ & $1.6(1.3$ to 2.0$)$ \\
\hline Not available/not applicable & $851(20)$ & $658,783(18)$ & $1.6(1.5$ to 1.8$)$ \\
\hline Multiple gestation & $181(4)$ & $56,806(2)$ & $2.9(2.5$ to 3.3$)$ \\
\hline Stillbirth & $190(5)$ & $19,649(0.5)$ & $8.8(7.6$ to 10.2$)$ \\
\hline
\end{tabular}

*Significant unadjusted odds ratios $(P<0.05)$ in bold text.

$\mathrm{CI}=$ confidence interval.

anesthesia for either labour or Cesarean delivery, general anesthesia (OR, 10.7; 95\% CI, 9.3 to 12.4) and general with neuraxial anesthesia (OR, 7.2; 95\% CI, 5.4 to 9.7) were associated with the highest odds of developing sepsis (ESM eTable 2).

Surgical procedures including peripartum hysterectomy (OR, 4.9; 95\% CI, 3.6 to 6.6), dilatation and curettage (OR, $1.8 ; 95 \% \mathrm{CI}, 1.6$ to 2.1 ), and interventions such as artificial rupture of membranes (OR, 1.1; 95\% CI, 1.0 to 1.3) significantly increased the odds of developing sepsis. Several obstetrical and maternal comorbidities were found to be associated with sepsis (Table 3). Significant obstetrical conditions included chorioamnionitis (OR, 7.6; 95\% CI, 6.9 to 8.3), postpartum hemorrhage (OR, 2.9; 95\% CI, 2.7 to 3.2), retained products of conception (OR, 1.6 (95\% CI, 1.2 to 2.1 ), preeclampsia/eclampsia (OR, 1.4; $95 \% \mathrm{CI}, 1.3$ to 1.6 ), placental abruption (OR, 1.4; $95 \% \mathrm{CI}$, 1.2 to 1.7 ), and gestational diabetes (OR, $1.2 ; 95 \% \mathrm{CI}, 1.1$ to 1.4$)$.

Medical conditions associated with sepsis included venous thromboembolism (OR, 16.2; 95\% CI, 11.6 to 22.6), maternal infectious/parasitic diseases (OR, 14.6;
95\% CI, 13.1 to 16.3 ), chronic renal disease (OR, 8.6; $95 \%$ CI, 6.7 to 11.1), cerebrovascular disease (OR, 8.0; 95\% CI, 4.3 to 14.6$)$, respiratory disease (OR, $6.6 ; 95 \% \mathrm{CI}, 5.8$ to 7.6), liver disease (OR, 6.2; 95\% CI, 4.4 to 8.9), gastrointestinal disease (OR, 5.5; 95\% CI, 4.6 to 6.5), valvular heart disease (OR, 6.2; 95\% CI, 4.1 to 9.4), sickle cell disease (OR, 5.3; 95\% CI, 3.0 to 9.3), anemia (OR, 3.9; 95\% CI, 3.5 to 4.3 ), drug abuse and dependence (OR, 2.8; 95\% CI, 2.3 to 3.5 ), diabetes mellitus (OR, $1.5 ; 95 \% \mathrm{CI}$, 1.1 to 2.2 ), pre-existing hypertension (OR, $1.4 ; 95 \% \mathrm{CI}, 1.1$ to 1.8 ), and obesity (OR, $1.3 ; 95 \% \mathrm{CI}, 1.0$ to 1.5 ). Associations between uncommon obstetrical procedures, medical conditions, and sepsis are presented in ESM eTable 3.

\section{Severe sepsis vs nonsevere sepsis}

\section{Associations with severe sepsis}

Of the 4,130 incidences of maternal sepsis, 568 (14\%) were classified as severe. Implementation of prophylactic antibiotic use prior to incision for Cesarean delivery in 
Table 3 Unadjusted and adjusted associations between delivery method, obstetrical surgical procedures, obstetric conditions, medical conditions, and maternal sepsis

\begin{tabular}{|c|c|c|c|c|}
\hline & $\begin{array}{l}\text { Sepsis }(\%) \\
n=4,183\end{array}$ & $\begin{array}{l}\text { No sepsis }(\%) \\
n=3,649,600\end{array}$ & $\begin{array}{l}\text { Unadjusted odds ratio } \\
(95 \% \mathrm{CI})\end{array}$ & $\begin{array}{l}\text { Adjusted odds ratio } \\
(95 \% \text { CI })\end{array}$ \\
\hline \multicolumn{5}{|l|}{ Delivery method ${ }^{\mathrm{b}}$} \\
\hline Manually assisted vaginal $^{\mathrm{c}}$ & $1,495(36 \%)$ & $2,247,098(62 \%)$ & Reference & Reference \\
\hline Unassisted spontaneous vaginal $^{\mathrm{d}}$ & $5(0.1 \%)$ & $4,108(0.1 \%)$ & $1.8(0.77$ to 4.4$)$ & $1.1(0.46$ to 2.7$)$ \\
\hline Instrumental vaginal $^{\mathrm{e}}$ & $438(11 \%)$ & $374,545(10 \%)$ & $1.8(1.6$ to 2.0$)$ & 1.5 (1.3 to 1.7$)$ \\
\hline Cesarean & $2,229(53 \%)$ & $1,020,333(28 \%)$ & $3.3(3.1$ to 3.5$)$ & $3.2(3.0$ to 3.5$)$ \\
\hline Other & $36(0.9 \%)$ & $9,141(0.3 \%)$ & $5.8(4.3$ to 8.3$)$ & $1.1(0.78$ to 1.6$)$ \\
\hline \multicolumn{5}{|c|}{ Obstetrical surgical procedure/intervention ${ }^{\mathrm{f}}$} \\
\hline Peripartum hysterectomy & $48(1 \%)$ & $1,748(<0.1 \%)$ & $24.2(18.2$ to 32.3$)$ & $4.9(3.6$ to 6.6$)$ \\
\hline Cervical cerclage & $12(0.3 \%)$ & $445(<0.1 \%)$ & $23.6(13.3$ to 41.9$)$ & 1.9 (0.99 to 3.4$)$ \\
\hline Dilatation and curettage & $480(12 \%)$ & $125,979(4 \%)$ & $3.6(3.3$ to 4.0$)$ & $1.8(1.6$ to 2.1$)$ \\
\hline Artificial rupture of membranes & $377(9 \%)$ & $310,528(9 \%)$ & $1.1(0.96$ to 1.2$)$ & $1.1(1.0$ to 1.3$)$ \\
\hline Postpartum surgical repair & $1,100(26 \%)$ & $1,482,222(41 \%)$ & $0.52(0.49$ to 0.6$)$ & 1.1 (0.98 to 1.2$)$ \\
\hline Assisted reproductive technology & $119(3 \%)$ & $53,303(2 \%)$ & $2.0(1.7$ to 2.4$)$ & $1.1(0.88$ to 1.3$)$ \\
\hline Manual removal of placenta & $172(4 \%)$ & $59,518(2 \%)$ & $2.6(2.2$ to 3.0$)$ & $0.86(0.71$ to 1.1$)$ \\
\hline \multicolumn{5}{|l|}{ Obstetric conditions ${ }^{\mathrm{f}}$} \\
\hline Chorioamnionitis & $584(14 \%)$ & $35,648(1 \%)$ & 16.5 (15.1 to 18.0$)$ & $7.6(6.9$ to 8.3$)$ \\
\hline Postpartum hemorrhage & $862(21 \%)$ & $225,763(6 \%)$ & 3.9 (3.7 to 4.2$)$ & $2.9(2.7$ to 3.2$)$ \\
\hline Retained products of conception & $73(2 \%)$ & $30,129(0.8 \%)$ & 2.1 (1.7 to 2.7$)$ & $1.6(1.2$ to 2.1$)$ \\
\hline Placental abruption & $181(4 \%)$ & $42,744(1 \%)$ & $3.8(3.3$ to 4.4$)$ & $1.4(1.2$ to 1.7$)$ \\
\hline Preeclampsia and eclampsia & $461(11 \%)$ & $199,994(6 \%)$ & $2.1(1.9$ to 2.4$)$ & $1.4(1.3$ to 1.6$)$ \\
\hline Gestational diabetes & $377(9 \%)$ & $234,199(6 \%)$ & $1.5(1.3$ to 1.6$)$ & $1.2(1.1$ to 1.4$)$ \\
\hline Morbidly adherent placenta & $26(0.7 \%)$ & $3,428(0.1 \%)$ & $6.7(4.5$ to 9.8$)$ & $1.0(0.68$ to 1.6$)$ \\
\hline Placenta previa & $60(1 \%)$ & $23,002(0.6 \%)$ & $2.3(1.8$ to 3.0$)$ & $0.74(0.57$ to 0.97$)$ \\
\hline \multicolumn{5}{|l|}{ Medical conditions ${ }^{\mathrm{f}}$} \\
\hline Venous thromboembolism & $40(1 \%)$ & $1,476(<0.1 \%)$ & $23.9(17.4$ to 32.7$)$ & $16.2(11.6$ to 22.6$)$ \\
\hline Other puerperal infections & $438(11 \%)$ & $11,368(0.3 \%)$ & $37.4(33.9$ to 41.4$)$ & $16.2(14.5$ to 18.0$)$ \\
\hline Infectious and parasitic diseases & $400(10 \%)$ & $17,900(0.5 \%)$ & $21.5(19.3$ to 23.8$)$ & $14.6(13.1$ to 16.3$)$ \\
\hline Chronic renal disease & $70(2 \%)$ & $3,715(0.1 \%)$ & 16.7 (13.2 to 21.2$)$ & $8.6(6.7$ to 11.1$)$ \\
\hline Cerebrovascular disease & $12(0.3 \%)$ & $576(<0.1 \%)$ & $18.2(10.3$ to 32.3$)$ & $8.0(4.3$ to 14.6$)$ \\
\hline Malignancy & $16(0.4 \%)$ & $1,269(<0.1 \%)$ & $11.0(6.7$ to 18.1$)$ & $6.7(4.0$ to 11.1$)$ \\
\hline Respiratory diseases $^{\mathrm{g}}$ & $243(6 \%)$ & $18,122(0.5 \%)$ & $12.4(10.9$ to 14.1$)$ & $6.6(5.8$ to 7.6$)$ \\
\hline Liver disease ${ }^{\mathrm{h}}$ & $32(0.8 \%)$ & $3,129(0.1 \%)$ & $9.0(6.3$ to 12.8$)$ & $6.2(4.4$ to 8.9$)$ \\
\hline Valvular heart disease & $23(0.5 \%)$ & $2,579(0.1 \%)$ & $7.8(5.2$ to 11.8$)$ & $6.2(4.1$ to 9.4$)$ \\
\hline Gastrointestinal diseases & $144(3 \%)$ & $15,439(0.4 \%)$ & $8.4(7.1$ to 9.9$)$ & $5.5(4.6$ to 6.5$)$ \\
\hline Sickle cell disease & $13(0.3 \%)$ & $1,359(<0.1 \%)$ & $8.4(4.8$ to 14.5$)$ & $5.3(3.0$ to 9.3$)$ \\
\hline Anemia & $642(15 \%)$ & $74,685(2 \%)$ & $8.7(8.0$ to 9.4$)$ & $3.9(3.5$ to 4.3$)$ \\
\hline Drug abuse and dependence & $94(2 \%)$ & $21,879(0.6 \%)$ & $3.8(3.1$ to 4.7$)$ & $2.8(2.3$ to 3.5$)$ \\
\hline Liver disorders & $41(1 \%)$ & $15,294(0.4 \%)$ & $2.4(1.7$ to 3.2$)$ & $2.2(1.6$ to 3.0$)$ \\
\hline Diabetes mellitus & $32(0.8 \%)$ & $8,604(0.2 \%)$ & $3.3(2.3$ to 4.6$)$ & $1.5(1.1$ to 2.2$)$ \\
\hline Pre-existing hypertension & $64(2 \%)$ & $26,361(0.7 \%)$ & $2.1(1.7$ to 2.7$)$ & $1.4(1.1$ to 1.8$)$ \\
\hline Obesity & $115(3 \%)$ & $51,893(1 \%)$ & $2.0(1.6$ to 2.4$)$ & $1.3(1.0$ to 1.5$)$ \\
\hline
\end{tabular}


Table 3 continued

CI = confidence interval; ICD-10 = International Classification of Diseases Tenth Revision, Canada.

a Odds ratios adjusted for demographic variables (age, parity, multiple gestation, stillbirths), delivery method (assisted vaginal [reference], spontaneous vaginal, instrumental vaginal, Cesarean), surgical procedures (peripartum hysterectomy, dilatation and curettage, postpartum hemorrhage), and obstetrical conditions (placental abruption, chorioamnionitis, gestational diabetes, preeclampsia/eclampsia). Significant adjusted odds ratios $(P<0.05)$ in bold text.

b Total number of deliveries under sepsis $(n=4,203)$ and no sepsis $(n=3,655,225)$ does not equal 4,183 and 3,649,600, respectively. More than one delivery method (e.g., vaginal and Cesarean) could have been associated with a single hospitalization.

${ }^{c}$ Includes manually assisted vaginal deliveries with and without episiotomy (ICD-10: 5MD50^). e.g., Crede maneuver, slipping cord over head of the fetus, version and/or rotation at time of delivery, turning the fetus in utero with the hand or fingers inside the uterus, Pomeroy maneuver etc.

${ }^{\mathrm{d}}$ Includes unassisted spontaneous vaginal deliveries (ICD-10: 5MD51^)

${ }^{\mathrm{e}}$ Includes forceps, vacuum or combination of forceps, and vacuum with or without episiotomy (ICD-10: $5 \mathrm{MD} 53^{\wedge}-55^{\wedge}$ )

${ }^{\mathrm{f}}$ Procedures and conditions with less than ten cases in the sepsis group are presented in Electronic Supplementary Material eTable 2.

g Includes diseases of the respiratory system that complicate pregnancy, childbirth, and puerperium,

such as chronic lower respiratory disease and asthma

h Includes hepatitis, hepatic failure, toxic liver disease

2010 did not reduce the odds of developing severe sepsis (OR, $0.90 ; 95 \% \mathrm{CI}, 0.76$ to 1.1 ). Women $\geq 35$ years of age (OR, 1.5; 95\% CI, 1.2 to 1.8 ) presented increased odds of developing severe sepsis compared with nonsevere sepsis compared with parturients aged 25-34 years (Table 4). Preterm deliveries (20-36 weeks) were associated with severe sepsis (OR, 3.1; 95\% CI, 2.5 to 3.8) compared with term pregnancies (Table 4). Stillbirths (OR, 6.6; 95\% CI, 4.9 to 8.9 ) presented with increased odds of severe sepsis compared with nonsevere sepsis.

Associations between severe sepsis and delivery method, obstetrical surgical procedures, and obstetric and medical conditions are presented in Table 5. Cesarean (OR, $2.8 ; 95 \% \mathrm{CI}, 2.2$ to 3.6$)$ and instrumental vaginal deliveries (OR, 1.9; 95\% CI, 1.3 to 2.8 ) were more significantly associated with severe sepsis than assisted vaginal deliveries were. Peripartum hysterectomy (OR, 10.9; 95\% $\mathrm{CI}, 5.3$ to 22.5$)$ and dilatation and curettage (OR, 1.4; $95 \%$ CI, 1.0 to 2.0) were associated with severe sepsis. Obstetric conditions associated with increased odds of severe sepsis included postpartum hemorrhage (OR, 2.4; 95\% CI, 1.9 to 3.1), preeclampsia/eclampsia (OR, $1.9 ; 95 \% \mathrm{CI}, 1.4$ to 2.4$)$, and chorioamnionitis (OR, 1.4; 95\% CI, 1.1 to 1.8). Several medical conditions were associated with higher odds of severe sepsis including valvular heart disease (OR, 20.1; $95 \% \mathrm{CI}, 7.1$ to 56.4 ), respiratory disease (OR, $8.4 ; 95 \% \mathrm{CI}$, 6.2 to 11.4 ), chronic renal disease (OR, $6.2 ; 95 \% \mathrm{CI}, 3.7$ to 10.6), gastrointestinal disease (OR, 3.7; 95\% CI, 2.5 to 5.5), infectious and parasitic disease (OR, 2.9; 95\% CI, 2.3 to 3.8), drug abuse and dependence (OR, 2.5; 95\% CI, 1.5 to 4.2 ), anemia (OR, 2.3; 95\% CI, 1.9 to 2.9 ), and other puerperal infections (OR, 1.5; 95\% CI, 1.1 to 2.0). Associations between uncommon obstetrical procedures, medical conditions, and sepsis are presented in ESM eTable 4.

\section{Discussion}

This is the first Canada-wide population-based study on the epidemiology of maternal sepsis. In a cohort of over 3.6 million women hospitalized for delivery over 13 years, we observed that one in 877 developed sepsis, with a case fatality rate of $0.5 \%$. We also found that one in seven women with sepsis developed severe sepsis-related morbidity or mortality.

While the incidence of maternal sepsis of 114 per 100,000 hospitalizations decreased by 35\% from 2004 to 2016 in Canada, it remains up to three times higher than that observed in the UK and USA during the early 2010s, although the methodological approaches of these studies differ. ${ }^{7,10}$ Furthermore, the case fatality rate from sepsis in Canada was $0.5 \%$, significantly lower than rates as high as $12 \%$ at the turn of the century in the USA, but in line with 2015 figures of approximately $2 \% .^{20}$ Country-specific differences may be explained by differences in healthcare system, ${ }^{7}$ institutional practices, cohort demographics and changing sepsis definitions. ${ }^{5}$ The case fatality rate in our cohort of patients was over 50 times higher than the maternal mortality rate in Canada. ${ }^{21}$ While most cases of 
Table 4 Associations between patient characteristics and severe sepsis

\begin{tabular}{|c|c|c|c|}
\hline Characteristics & Severe sepsis $(\%) n=568$ & Nonsevere sepsis (\%) $n=3,615$ & Unadjusted odds ratio $^{\mathrm{a}}(95 \% \mathrm{CI})$ \\
\hline \multicolumn{4}{|l|}{ Maternal age (years) } \\
\hline$<25$ & $112(20 \%)$ & $984(27 \%)$ & $0.73(0.58$ to 0.92$)$ \\
\hline $25-34$ & $304(54 \%)$ & $1,958(54 \%)$ & Reference \\
\hline $35-39$ & $116(20 \%)$ & $533(15 \%)$ & $1.4(1.1$ to 1.8$)$ \\
\hline$\geq 40$ & $36(6 \%)$ & $140(4 \%)$ & $1.7(1.1$ to 2.4$)$ \\
\hline \multicolumn{4}{|l|}{ Gestational age (weeks) } \\
\hline $20-28$ & $78(14 \%)$ & $172(5 \%)$ & $3.8(2.8$ to 5.1$)$ \\
\hline $29-32$ & $46(8 \%)$ & $118(3 \%)$ & $3.2(2.2$ to 4.7$)$ \\
\hline $33-36$ & $85(15 \%)$ & $280(78 \%)$ & $2.5(1.9$ to 3.4$)$ \\
\hline $37-40$ & $199(35 \%)$ & $16,554(46 \%)$ & Reference \\
\hline$\geq 41$ & $35(6 \%)$ & $355(10 \%)$ & $0.82(0.56$ to 1.2$)$ \\
\hline Unknown & $125(22 \%)$ & $1,036(29 \%)$ & $1.0(0.79$ to 1.3$)$ \\
\hline \multicolumn{4}{|l|}{ Parity } \\
\hline 0 & $247(44 \%)$ & $1,810(50 \%)$ & $0.59(0.45$ to 0.78$)$ \\
\hline 1 & $114(20 \%)$ & $594(16 \%)$ & $0.83(0.61$ to 1.1$)$ \\
\hline $2-3$ & $82(14 \%)$ & $355(10 \%)$ & Reference \\
\hline$\geq 4$ & $32(6)$ & $98(3 \%)$ & $1.4(0.89$ to 2.3$)$ \\
\hline Not available/not applicable & $93(16)$ & $758(2 \% 1)$ & $0.53(0.39$ to 0.73$)$ \\
\hline Multiple gestation (yes) & $23(4)$ & $158(4 \%)$ & $0.92(0.59$ to 1.44$)$ \\
\hline Stillbirth (yes) & $90(16)$ & $100(3 \%)$ & $6.6(4.9$ to 8.9$)$ \\
\hline
\end{tabular}

${ }^{a} \mathrm{Si} \mathrm{CI}=$ confidence interval.

gnificant unadjusted odds ratios $(P<0.05)$ in bold text.

sepsis were in Ontario, incidence rates were nearly double the national average in the remote northern parts of the country, possibly because of disparities in healthcare resources and infrastructure.

Several factors, such as low maternal age, extremes of parity, instrumental vaginal delivery, and Cesarean delivery were associated with maternal sepsis in our population, consistent with studies in the UK and USA. $^{5,22,23}$ Nevertheless, our analysis also identified several new associations that have been unreported or only sparsely reported in other national trials. These included stillbirths, artificial rupture of membranes, retained products of conception, and surgical procedures such as hysterectomy, cervical cerclage, and dilatation and curettage, as well as obstetric conditions such as postpartum hemorrhage, preeclampsia/eclampsia, and placental abruption. $^{20,24,25}$ These factors may contribute to increased uterine atony, myometrial dysfunction and increased wound infection, conferring additional sepsis risk. ${ }^{26}$ Interestingly, sepsis, preeclampsia, and postpartum hemorrhage- three acutely (and possibly compounding) ${ }^{27}$ causes of maternal morbidity-were strongly associated with each other and have previously been proposed to be epidemiological markers for maternal health. ${ }^{8}$ We also observed that women with chorioamnionitis had up to seven times higher odds of developing sepsis. This explains the high rate of puerperal sepsis in our population. Furthermore, our finding of associations between anemia, diabetes, and sepsis is well-established, considering that these conditions contribute to impaired innate immunity. ${ }^{22,23} \mathrm{We}$ observed a significant reduction in hospitalizations for sepsis after implementation of recommendation of antibiotic administration prior to skin incision during Cesarean deliveries, which strengthens the importance of this practice.

The rate of progression to severe sepsis in our population was $14 \%$, with cardiovascular and respiratory systems primarily affected; similar to populations studied in the UK. ${ }^{23,25}$ One third of organ failure cases in our study involved multiple organs. Particularly, impairment of cardiorespiratory remodelling during pregnancy may interact with complex immunological and metabolic changes, conferring additional risk of organ failure. ${ }^{28}$ With over half of severe sepsis patients requiring admission to the ICU and high ICU-associated mortality, ${ }^{22,25}$ our analysis suggests prevention of organ 
Table 5 Unadjusted and adjusted associations between delivery method, obstetrical surgical procedures, obstetric conditions, medical conditions, and severe sepsis

\begin{tabular}{|c|c|c|c|c|}
\hline & $\begin{array}{l}\text { Severe } \\
\text { sepsis }(\%) n=568\end{array}$ & $\begin{array}{l}\text { Nonsevere } \\
\text { sepsis }(\%) n=3,615\end{array}$ & $\begin{array}{l}\text { Unadjusted odds } \\
\text { ratio }(95 \% \mathrm{CI})\end{array}$ & $\begin{array}{l}\text { Adjusted odds } \\
\text { ratio }^{\mathrm{a}}(95 \% \mathrm{CI})\end{array}$ \\
\hline \multicolumn{5}{|l|}{ Delivery method $^{\mathrm{b}}$} \\
\hline Manually assisted vaginal $^{c}$ & $149(26 \%)$ & $1,346(37 \%)$ & Reference & Reference \\
\hline $\begin{array}{l}\text { Unassisted spontaneous } \\
\text { vaginal }^{\mathrm{d}}\end{array}$ & $1(0.2 \%)$ & $4(0.1 \%)$ & $2.3(0.25$ to 20.3$)$ & $2.1(0.15$ to 28.6$)$ \\
\hline Instrumental vaginal $^{\mathrm{e}}$ & $54(9 \%)$ & $384(11 \%)$ & $1.3(0.91$ to 1.8$)$ & $1.9(1.3$ to 2.8$)$ \\
\hline Cesarean & $359(63 \%)$ & $1,870(52 \%)$ & $1.7(1.4$ to 2.1$)$ & $2.8(2.2$ to 3.6$)$ \\
\hline Other & $7(1 \%)$ & $29(0.8 \%)$ & $2.2(0.94$ to 5.1$)$ & $0.48(0.18$ to 1.3$)$ \\
\hline \multicolumn{5}{|l|}{ Obstetrical surgical procedure ${ }^{f}$} \\
\hline Peripartum hysterectomy & $37(7 \%)$ & $11(0.3 \%)$ & 22.8 (11.6 to 45.0$)$ & $10.9(5.3$ to 22.5$)$ \\
\hline Dilatation and curettage & $114(20 \%)$ & $366(10 \%)$ & $2.2(1.8$ to 2.8$)$ & $1.4(1.0$ to 3.0$)$ \\
\hline $\begin{array}{l}\text { Artificial rupture of } \\
\text { membranes }\end{array}$ & $51(9 \%)$ & $326(9 \%)$ & $1.0(0.73$ to 1.4$)$ & $1.2(0.82$ to 1.6$)$ \\
\hline Postpartum surgical repair & $119(21 \%)$ & $981(27 \%)$ & $0.71(0.57$ to 0.88$)$ & $1.2(0.90$ to 1.6$)$ \\
\hline $\begin{array}{l}\text { Assisted reproductive } \\
\text { technology }\end{array}$ & $18(3 \%)$ & $101(3 \%)$ & $1.1(0.68$ to 1.9$)$ & $0.74(0.41$ to 1.3$)$ \\
\hline Manual removal of placenta & $33(6 \%)$ & $139(4 \%)$ & $1.5(1.0$ to 2.3$)$ & $0.71(0.41$ to 1.2$)$ \\
\hline \multicolumn{5}{|l|}{ Obstetric conditions ${ }^{\mathrm{f}}$} \\
\hline Postpartum hemorrhage & $205(36 \%)$ & $657(18 \%)$ & $2.5(2.1$ to 3.1$)$ & $2.4(1.9$ to 3.1$)$ \\
\hline Preeclampsia and eclampsia & $98(17 \%)$ & $363(10 \%)$ & $1.9(1.5$ to 2.4$)$ & $1.9(1.4$ to 2.4$)$ \\
\hline Chorioamnionitis & $125(22 \%)$ & $459(13 \%)$ & $1.9(1.6$ to 2.4$)$ & $1.4(1.1$ to 1.8$)$ \\
\hline Placental abruption & $46(8 \%)$ & $135(4 \%)$ & 2.3 (1.6 to 3.2$)$ & $1.2(0.83$ to 1.8$)$ \\
\hline Gestational diabetes & $66(12 \%)$ & $311(9 \%)$ & $1.4(1.1$ to 1.9$)$ & $1.1(0.77$ to 1.5$)$ \\
\hline Morbidly adherent placenta & $10(2 \%)$ & $16(0.4 \%)$ & $4.0(1.8$ to 8.9$)$ & $0.65(0.23$ to 1.8$)$ \\
\hline Placenta previa & $11(2 \%)$ & $49(1 \%)$ & $1.4(0.74$ to 2.8$)$ & $0.47(0.21$ to 1.1$)$ \\
\hline \multicolumn{5}{|l|}{ Medical conditions ${ }^{\mathrm{f}}$} \\
\hline Valvular heart disease & $17(3 \%)$ & $6(0.2 \%)$ & $18.6(7.3$ to 47.3$)$ & $20.1(7.1$ to 56.4$)$ \\
\hline Respiratory diseases & $134(24 \%)$ & $109(3 \%)$ & 9.9 (7.6 to 13.0$)$ & $8.4(6.2$ to 11.4$)$ \\
\hline Chronic renal disease & $36(6 \%)$ & $34(0.9 \%)$ & 7.1 (4.4 to 11.5$)$ & $6.2(3.7$ to 10.6$)$ \\
\hline Gastrointestinal diseases & $61(11 \%)$ & $83(2 \%)$ & 5.1 (3.6 to 7.2 ) & $3.7(2.5$ to 5.5$)$ \\
\hline $\begin{array}{l}\text { Infectious and parasitic } \\
\text { diseases }\end{array}$ & $125(22 \%)$ & $275(8 \%)$ & $3.4(2.7$ to 4.3$)$ & $2.9(2.3$ to 3.8$)$ \\
\hline Drug abuse and dependence & $29(5 \%)$ & $65(2 \%)$ & $2.9(1.9$ to 4.6$)$ & $2.5(1.5$ to 4.2$)$ \\
\hline Anemia & $173(31 \%)$ & $469(13 \%)$ & 2.9 (2.4 to 3.6$)$ & $2.3(1.8$ to 2.9$)$ \\
\hline Other puerperal infections & $86(15 \%)$ & $352(10 \%)$ & $1.7(1.3$ to 2.1$)$ & $1.5(1.1$ to 2.0$)$ \\
\hline Obesity & $25(4 \%)$ & $90(3 \%)$ & $1.8(1.2$ to 2.8$)$ & $0.97(0.58$ to 1.6$)$ \\
\hline
\end{tabular}

$\mathrm{CI}=$ confidence interval; ICD-10 = International Classification of Diseases Tenth Revision, Canada.

a Odds ratios adjusted for demographic variables (age, parity, multiple gestation, stillbirths), delivery method (assisted vaginal [reference], spontaneous vaginal, instrumental vaginal, Cesarean), surgical procedures (peripartum hysterectomy, dilatation and curettage, postpartum hemorrhage) and obstetrical conditions (placental abruption, chorioamnionitis, gestational diabetes, preeclampsia/eclampsia). Significant adjusted odds ratios $(P<0.05)$ in bold text.

b Total number of deliveries under severe sepsis $(n=570)$ and nonsevere sepsis $(n=3,633)$ does not equal 568 and 3,615, respectively. More than one delivery method (e.g., vaginal and Cesarean) could have been associated with a single hospitalization.

${ }^{c}$ Includes manually assisted vaginal deliveries with and without episiotomy (ICD-10: 5MD50^).

${ }^{\mathrm{d}}$ Includes unassisted spontaneous vaginal deliveries (ICD-10: 5MD51^).

${ }^{\mathrm{e}}$ Includes forceps, vacuum, or combination of forceps and vacuum with or without episiotomy (ICD-10: 5MD53^-55^).

${ }^{\mathrm{f}}$ Procedures and conditions with less than ten cases in the sepsis group are presented in Electronic Supplementary Material eTable 3. 
failure warrants early diagnosis, intervention, and strict monitoring of hemodynamic status to prevent further deterioration. Lack of resources, expertise of tertiary care centres, and delayed interventions in remote areas may have contributed to the observed regional variation in sepsis rates in our study.

Confidential enquiries into maternal deaths due to sepsis in the UK have suggested that early detection and high clinical suspicion are paramount and may be able to improve outcomes at the patient level. ${ }^{29}$ Associations identified in our study such as early gestation, valvular heart disease, respiratory or renal conditions, preeclampsia/ eclampsia, postpartum hemorrhage, and peripartum hysterectomy increase the odds of progression to severe sepsis up to 20 times. Increased physician vigilance in patients with these conditions may aid in risk stratification. While more routine use of the quick Sepsis Related Organ Failure Assessment, Maternal Early Obstetric Warning System, and the Sepsis in Obstetrics scores have been proposed, these scores do not include many of the risk factors we identified. ${ }^{30}$ Furthermore, there are too few evaluations of these diagnostic tools to determine their impact on reducing maternal morbidity and mortality. ${ }^{30,31}$ These bedside tests may be useful in diagnosing sepsis early, but may not be effective in a priori prediction of sepsis risk. This is supported by findings of Kendle et al. who showed that women with sepsis had a ten times higher rate of common comorbidities and right-shift in their Obstetric Comorbidity Index than those without sepsis. ${ }^{7}$ Although the Third International Consensus Definitions for Sepsis and Septic Shock (Sepsis-3) were published recently for uniformity, ${ }^{32}$ lack of validation of its diagnostic tools in pregnancy led to an obstetric-specific consensus definition by the WHO in $2017 .{ }^{33}$ This will have to be implemented in future studies and ICD coding for sepsis. It is possible that the COVID-19 pandemic may have added to the burden of sepsis and severe sepsis in obstetric population; however, these data are currently not available. Regardless, management controversies for sepsis still remain with respect to "sepsis bundles" for early recognition, glycemic control, steroid use, vasopressor and oxygen use, and intravenous immunoglobulin. ${ }^{9}$

The strength of this study is that it is the first and largest population-based study on the epidemiology of sepsis in Canada. Nevertheless, this study does not include data from Quebec because these data are not stored in the CIHI database. Furthermore, there is a potential for underreporting or misclassification of data; however, the accuracy of this database has been validated previously. ${ }^{11-14}$ The database also does not contain ethnic and socioeconomic data, which has previously been shown to correlate with maternal sepsis. ${ }^{7,10}$ The pathogen causing sepsis $^{34}$ and length of hospital stay ${ }^{25}$ associated with hospitalization are also not reported, and may be an area for future research in Canada. Furthermore, patients who died or were admitted to the ICU were often linked with multiple diagnostic codes, one of which was sepsis. Therefore, while sepsis was likely an important factor, it may not have been the sole cause of ICU admittance or death in some patients. Inability to collect neonatal data is also one of the limitations; however, this was not an outcome of interest of this study.

Maternal sepsis rates in Canada remain high, with large disparities in northern territories, which warrants improved resource stratification or use as a maternal health indicator like in Europe. ${ }^{8}$ We highlighted several associations with sepsis (chorioamnionitis, hysterectomy, Cesarean deliveries, venous thromboembolism etc.), which may warrant increased clinical vigilance. Strict adherence and improved management of these pre-existing conditions may therefore help to mitigate sepsis risk, ${ }^{29}$ although prospective and randomized controlled trials may be difficult to conduct in this context. Appropriate allocation of resources to underprivileged areas and health policy level changes are needed to improve patient outcomes.

Author contributions Indranil Balki helped with study design and development, data analysis and interpretation, and manuscript writeup. Leyla Baghirzada helped with study design and development, data analysis and interpretation, and manuscript editing for critical content. Andrew Walker helped with study design and development, data analysis and interpretation, and manuscript editing for critical content. Stephen Lapinsky helped with study design and development, data analysis and interpretation, and manuscript editing for critical content. Mrinalini Balki helped with study design and development, data analysis and interpretation, and manuscript editing for critical content.

Disclosures This study received the Best Paper in Obstetric Anesthesia award (Resident or Medical Student Category) at the Canadian Anesthesiologists' Society Annual Meeting, Canada, 20-21 June 2020.

Conflicts of interest The authors declare no competing interests.

Funding statement The study was supported by a grant from the Anesthesia Academic Council, Department of Anesthesiology, Perioperative and Pain Medicine, University of Calgary. Dr. Mrinalini Balki was supported by Merit awards, University of Toronto, Toronto.

Editorial responsibility This submission was handled by Dr. Philip M. Jones, Deputy Editor-in-Chief, Canadian Journal of Anesthesial Journal canadien d'anesthésie. 


\section{References}

1. Rudd KE, Johnson SC, Agesa KM, et al. Global, regional, and national sepsis incidence and mortality, 1990-2017: analysis for the Global Burden of Disease Study. Lancet 2020; 395: 200-11.

2. Acosta CD, Kurinczuk JJ, Lucas DN, Tuffnell DJ, Sellers S, Knight M. Severe maternal sepsis in the UK, 2011-2012: a national case-control study. PLoS Med 2014; DOI: https://doi. org/10.1371/journal.pmed.1001672.

3. World Health Organization. Sepsis. Available from URL: https:// www.who.int/news-room/fact-sheets/detail/sepsis (accessed September 2021).

4. Napolitano LM. Sepsis 2018: definitions and guideline changes. Surg Infect (Larchmt) 2018; 19: 117-25.

5. Hensley MK, Bauer ME, Admon LK, Prescott HC. Incidence of maternal sepsis and sepsis-related maternal deaths 0 in the United States. JAMA 2019; 322: 890-2.

6. Kramer HM, Schutte JM, Zwart JJ, Schuitemaker NW, Steegers EA, van Roosmalen J. Maternal mortality and severe morbidity from sepsis in the Netherlands. Acta Obstet Gynecol Scand 2009; 88: 647-53.

7. Kendle AM, Salemi JL, Tanner JP, Louis JM. Delivery-associated sepsis: trends in prevalence and mortality. Am J Obstet Gynecol 2019; 220: P391.E1-16.

8. Zhang WH, Alexander S, Bouvier-Colle MH, Macfarlane A. Incidence of severe pre-eclampsia, postpartum haemorrhage and sepsis as a surrogate marker for severe maternal morbidity in a European population-based study: the MOMS-B survey. BJOG 2005; 112: 89-96.

9. Greer $O$, Shah NM, Johnson MR. Maternal sepsis update: current management and controversies. Obstet Gynaecol 2020; 22: 45-55.

10. Acosta CD, Knight M, Lee HC, Kurinczuk JJ, Gould JB, Lyndon $A$. The continuum of maternal sepsis severity: incidence and risk factors in a population-based cohort study. PLoS One 2013; DOI: https://doi.org/10.1371/journal.pone.0067175.

11. Lisonkova S, Liu S, Bartholomew S, Liston RM, Joseph KS; Maternal Health Study Group of the Canadian Perinatal Surveillance System. Temporal trends in maternal mortality in Canada II: estimates based on hospitalization data. J Obstet Gynaecol Can 2011; 33: 1020-30.

12. Joseph KS, Liu S, Rouleau J, et al. Severe maternal morbidity in Canada, 2003 to 2007: surveillance using routine hospitalization data and ICD-10CA codes. J Obstet Gynaecol Can 2010; 32: 837-46.

13. Wen $S W$, Huang L, Liston $R$, et al. Severe maternal morbidity in Canada, 1991-2001. CMAJ 2005; 173: 759-64.

14. Liu S, Joseph KS, Bartholomew S, et al. Temporal trends and regional variations in severe maternal morbidity in Canada, 2003 to 2007. J Obstet Gynaecol Can 2010; 32: 847-55.

15. Canadian Institute for Health Information. International Statistical Classification of Diseases and Related Health Problems, Tenth Revision; 2015.

16. Canadian Institute for Health Information. Canadian Classification of Health Information, Volume Three - Tabular List; 2015.

17. Bauer ME, Bateman BT, Bauer ST, Shanks AM, Mhyre JM. maternal sepsis mortality and morbidity during hospitalization for delivery: temporal trends and independent associations for severe sepsis. Anesth Analg 2013; 117: 944-50.

18. Canadian Institute for Health Information. In Focus: A National Look at Sepsis. Canadian Institute for Health Information (CIHI)
2009. Available from URL: https://secure.cihi.ca/free_products/ HSMR_Sepsis2009_e.pdf (accessed September 2021).

19. van Schalkwyk J, van Eyke N; Infectious Diseases Committee. Antibiotic prophylaxis in obstetric procedures. J Obstet Gynaecol Can 2010; 32: 878-84.

20. Al-Ostad G, Kezouh A, Spence AR, Abenhaim HA. Incidence and risk factors of sepsis mortality in labor, delivery and after birth: population-based study in the USA. J Obstet Gynaecol Res 2015; 41: 1201-6.

21. Statistics Canada. Number of maternal deaths and maternal mortality rates for selected causes; 2020. Available from URL: https://www150.statcan.gc.ca/t1/tbl1/en/tv.action?pid=13100756 01\&cubeTimeFrame.startYear=2017\&cubeTimeFrame.endYear= 2019\&referencePeriods $=20170101 \% 2 \mathrm{C} 20190101$ (accessed September 2021).

22. Mohamed-Ahmed O, Nair M, Acosta C, Kurinczuk JJ, Knight M. Progression from severe sepsis in pregnancy to death: a UK population-based case-control analysis. BJOG 2015; 122: 1506-15.

23. Acosta CD, Bhattacharya S, Tuffnell D, Kurinczuk JJ, Knight M. Maternal sepsis: a Scottish population-based case-control study. BJOG 2012; 119: 474-83.

24. Kankuri E, Kurki T, Carlson P, Hiilesmaa $V$. Incidence, treatment and outcome of peripartum sepsis. Acta Obstet Gynecol Scand 2003; 82: 730-5.

25. Acosta CD, Harrison DA, Rowan K, Lucas DN, Kurinczuk JJ, Knight $M$. Maternal morbidity and mortality from severe sepsis: a national cohort study. BMJ Open 2016; DOI: https://doi.org/10. 1136/bmjopen-2016-012323.

26. Bergström $S$. Infection-related morbidities in the mother, fetus and neonate. J Nutr 2003; 133(5 Suppl 2): 1656S-60S.

27. Kuklina EV, Ayala C, Callaghan WM. Hypertensive disorders and severe obstetric morbidity in the United States. Obstet Gynecol 2009; 113: 1299-306.

28. Kohlhepp LM, Hollerich G, Vo L, et al. Physiological changes during pregnancy (German). Anaesthesist 2018; 67: 383-96.

29. Cantwell R, Clutton-Brock T, Cooper $G$, et al. Saving Mothers' Lives: reviewing maternal deaths to make motherhood safer: 2006-2008. the eighth report of the confidential enquiries into maternal deaths in the United Kingdom. BJOG 2011; 118 Suppl 1: 1-203.

30. Burlinson CE, Sirounis D, Walley KR, Chau A. Sepsis in pregnancy and the puerperium. Int J Obstet Anesth 2018; 36: 96-107.

31. Bauer ME, Housey M, Bauer ST, et al. Risk factors, etiologies, and screening tools for sepsis in pregnant women: a multicenter case-control study. Anesth Analg 2019; 129: 1613-20.

32. Singer $M$, Deutschman CS, Seymour CW, et al. The Third International Consensus Definitions for Sepsis and Septic Shock (Sepsis-3). JAMA 2016; 315: 801-10.

33. Bonet $M$, Nogueira Pileggi V, Rijken MJ, et al. Towards a consensus definition of maternal sepsis: results of a systematic review and expert consultation. Reprod Health 2017; DOI: https://doi.org/10.1186/s12978-017-0321-6.

34. Knowles SJ, O'Sullivan NP, Meenan AM, Hanniffy R, Robson M. Maternal sepsis incidence, aetiology and outcome for mother and fetus: a prospective study. BJOG 2015; 122: 663-71.

Publisher's Note Springer Nature remains neutral with regard to jurisdictional claims in published maps and institutional affiliations. 